Universidad Nacional de La Plata.

Facultad de Humanidades y Ciencias de la Educación.

Centro de Investigaciones Socio Históricas

\title{
Batallando por la reactivación del liberalismo en la Argentina: la revista Ideas sobre la Libertad entre 1958 y 1976
}

\author{
Battling for the revival of liberalism in Argentina: the magazine Ideas \\ sobre la Libertad between 1958 and 1976
}

\begin{abstract}
Victoria Haidar *
* Centro de Investigaciones de la Facultad de Ciencias Jurídicas y Sociales de la Universidad Nacional del Litoral, Consejo Nacional de Investigaciones Científicas y Técnicas, Argentina I vhaidar@fcjs.unl.edu.ar
\end{abstract}

\section{PALABRAS CLAVE}

Liberalismo

Neoliberalismo

Batalla por las ideas

Argentina

\section{KEYWORDS}

Liberalism

Neoliberalism

Battle of ideas

Argentina

\section{RESUMEN}

A partir del análisis de Ideas sobre la Libertad, la revista del Centro de Estudios sobre la Libertad creado a instancias de Alberto Benegas Lynch, el artículo muestra el papel que, desde ese espacio, se atribuyó a dicha publicación en el marco de la "batalla por las ideas", explora las vinculaciones transnacionales que el mismo mantuvo con think-tanks e intelectuales que defendían el libre mercado, y reconstruye la significación que dio a la "reactivación" del liberalismo entre 1958 y 1976. Considerando esos tres ejes se argumenta que Ideas sobre la Libertad apuntaba a la educación de las elites mediante la crítica del colectivismo, la difusión y el comentario de la "tradición liberal argentina”. Asimismo se sostiene que el posicionamiento de aquella institución respecto del proyecto neoliberal era ambiguo, puesto que desde la revista se confrontaron las ideas "colectivistas" pero no se puso en discusión el rol del Estado. 


\section{Introducción}

En los últimos años un corpus de bibliografía referida al liberalismo ha venido a complejizar la comprensión del campo de las ideas políticas en la Argentina en el período que se extiende entre el golpe de Estado que derrocó al gobierno de Juan D. Perón y el comienzo de la última dictadura militar (1955-1976). Aludimos a una serie de aportes que, tendiendo a balancear el predominio de los trabajos dedicados a los intelectuales identificados con la izquierda y con el peronismo (Georgieff, 2008; Ponza, 2010; Sigal y Verón, 1988; Sigal, 2002; Terán, 1991), se ocupan de estudiar las configuraciones que asumieron el liberal-conservadurismo (Heredia, 2001, 2002; Llamazares Valduvieco, 1995; Morresi, 2010; Vicente, 2013a, 2013b, 2015) y el catolicismo liberal (Zanca, 2013); atienden a la difusión y el progresivo enraizamiento de ideas neoliberales en diversos círculos (Grondona 2011; Haidar, 2015a; Morresi, 2007, 2008, 2009, 2011) o bien analizan los modos en que ciertas “cuestiones” (así, el “desarrollo", la "legalidad”, etc.) fueron problematizadas, en aquellos años, desde diferentes puntos de vista liberales (Haidar 2015b, 2016a, 2016b).

Así, los trabajos de Llamazares Valduvieco, Vicente (2013a y 2013b), Zanca y Haidar, exploran el campo de las ideas políticas y/o de la cultura católica en los convulsionados años que transcurrieron entre la denominada Revolución Libertadora y el golpe de Estado de 1976, atendiendo, según los casos, a la inflexión que significó el peronismo para el campo del liberalismo, a las controversias que suscitaron tanto la integración de las masas al sistema político como la cuestión del “desarrollo argentino” y/o a las reconfiguraciones experimentadas en ámbito del cristianismo. Por su parte, sin dejar de considerar los modos en que ciertos intelectuales individuales y colectivos participaron de aquellos debates, los aportes de Heredia, Morresi y Vicente (2015) establecen diálogos fecundos con el período del llamado "Proceso de Reorganización Nacional” (1976-1983) y, en algunos casos (Heredia, 2002; Morresi, 2007, 2008), también con los años ‘ 90.

A horcajadas entre pasado y presente, el corpus bibliográfico al que antes nos referimos constituye un contexto más que sugerente para explorar la revista Ideas sobre la Libertad (en adelante IsL) entre la aparición de su primer número, en el mes de diciembre de 1958 y el golpe de Estado del 24 de marzo de 1976.

Órgano de expresión del Centro de Difusión de la Economía Libre (en adelante CDEL) creado en 1957 a instancias del empresario vitivinícola, economista, escritor y conferencista Alberto Benegas Lynch (19091999)ํㅗㄴ IsL apareció en un período clave tanto para la reorganización y renovación del campo liberal en la Argentina, como para la consolidación e institucionalización del neoliberalismo como un espacio de pensamiento colectivo de proporciones crecientemente globales (Plewhe, 2009:4)

A través del análisis de dicha publicación $\underline{2}$ en este artículo aspiramos a efectuar un aporte que permita profundizar, por un lado, la comprensión del liberalismo argentino en el período que transcurre entre los años post-peronistas y el comienzo de la última dictadura militar. Así, el trabajo reconstruye la significación que el CDEL atribuyó a la "reactivación” del liberalismo en el país, esclareciéndose el papel que IsL estaba destinada a cumplir en el marco de ese proyecto. Tal como argumentaremos, una estrategia clave en esa dirección consistió en la recuperación de ciertos textos, autores y símbolos procedentes de la tradición liberal $\operatorname{argentina}^{\underline{3}}$, los cuales fueron movilizados con la finalidad de apuntalar los valores y principios "pro mercado", como de defender una visión elitista de democracia.

Por otro lado, al explorar las vinculaciones que la institución que presidía Alberto Benegas Lynch mantenía con ciertos think-tanks y grupos de ideas situados en los Estados Unidos y en Latinoamérica, no menos que con intelectuales emblemáticos para la renovación del liberalismo en la II Postguerra, el trabajo aspira ampliar el conocimiento acerca de los procesos de articulación y organización de ideas y fuerzas a partir de los cuales el neoliberalismo se configuró, entre las décadas de 1940 y 1970, como un espacio y un estilo de 
pensamiento transnacional, con focos de producción y de divulgación de discursos, programas, estrategias, etc., situados en diversos países. En esta dirección, indaga en torno al modo -ambivalente- en que IsL participó de ese proyecto colectivo, el cual revestía, ya desde su despuntar en los años '30, un carácter plural, contradictorio y multi-centrado.

El artículo está organizado de la siguiente manera: el apartado 1 presenta, de manera sucinta, algunas referencias sobre el estado del campo liberal argentino en el que se inscribía IsL, atendiendo a la emergencia de iniciativas que involucraban una reactivación y/o renovación del liberalismo y, en especial, a la circulación temprana de ideas neoliberales. En el punto 2 se exploran los vínculos que el CDEL mantenía con las organizaciones que, en los Estados Unidos, militaban en pos del libre mercado, particularmente con la Foundation for Economic Education, al tiempo que se avanza en la comprensión del rol que IsL tenía en la “batalla por las ideas”. En el apartado 3 se sostiene la idea de que la participación de IsL en el proyecto neoliberal fue ambivalente. Así, se muestra cómo desde sus páginas se criticaron varias expresiones del “colectivismo" sin que se avanzara, no obstante, en la re-problematización del rol del Estado. Para pensar esta última figura así como otros problemas los intelectuales vinculados al CDEL optaron, en cambio, por recuperar la tradición liberal fundacional argentina, la cual fue integrada, tal como explicamos en el punto 4, a los debates políticos y económicos de la época. El artículo culmina con una serie de reflexiones finales.

\section{Reorganización y renovación del campo liberal argentino}

Considerando la prolongada crisis que experimentaba desde 1930 el liberalismo argentino, los años que siguieron al derrocamiento del peronismo resultaron claves para la reorganización y renovación del campo liberal, tanto en términos de acumulación de saber como de conformación de redes institucionales.

Es preciso destacar, no obstante, que las ideas de algunos de los intelectuales representativos del neoliberalismo, como von Mises y Hayek, circulaban en la Argentina ya desde los años '40. Habían ingresado tempranamente, vehiculizadas por políticos e intelectuales como Federico Pinedo, quién tomó contacto con ellas en un viaje juvenil a Europa, introduciéndolas durante los primeros años del peronismo, en el Parlamento, la prensa y en diversos grupos empresarios e intelectuales (Morresi, 2009, 2011).

Desde la década de 1920 estaban en desarrollo, en Europa, algunas de las discusiones que estructuraron, en los años subsiguientes, el “campo adversativo” (Foucault, 2012) del neoliberalismo ${ }^{4}$. Merece recordarse que el economista Ludwig von Mises -al cual Benegas Lynch se sentía próximo-, dirigió, en Viena, el famoso Privatseminar donde se inició el debate relativo al "cálculo socialista”, del cual participaron, entre otros, Oscar Morgenstern, Alfred Schütz y Fritz Machlup (Denord, 2002/5; Plehwe, 2009), y que fue continuado en Londres por Friedrich Hayek, otro ilustre integrante de aquel Seminario.

Dirigidas inicialmente hacia los fundamentos científicos de aquella corriente de pensamiento, tras la experiencia de la II Guerra Mundial dichas impugnaciones se radicalizaron, adquiriendo el tinte marcadamente político-ideológico con el que apareció planteada la condena al socialismo y a toda forma de colectivismo en Camino de servidumbre, el best seller de la literatura liberal que Hayek publicó en 1944. En una operación intelectual que aplanaba las diferencias entre regímenes democráticos, fascistas y totalitarios, ampliamente compartida por el grupo de ideas organizado en torno a Benegas Lynch, el economista austríaco sostenía que el peligro para las libertades radicaba en las medidas estatales de dirección de la economía, fundamentalmente, en las técnicas de planificación centralizadas, sea que estas se aplicasen en contextos democráticos o autoritarios. Desde ese punto de vista, que legitimó la orientación decisivamente contraria al Estado de Bienestar que caracterizó, en la II Postguerra, a los distintos linajes neoliberales, las regulaciones de la vida económica conducían, inexorablemente, al totalitarismo.

Así, mientras el cuestionamiento del socialismo data de los años '20, el segundo frente de ataque en torno al 
cual se organizaron las reflexiones de los neoliberales recién comenzó a perfilarse con nitidez a partir de la crisis económica de 1930, la cual fue percibida por toda una serie de intelectuales como un desafío para “revisar” las ideas del liberalismo clásico, en un esfuerzo por producir nuevas justificaciones políticas e ideológicas para el capitalismo.

El período de entreguerras se mostró particularmente fecundo, en varios países europeos, para poner en discusión el principio del "laissez faire”. Un punto de inflexión fue el Coloquio que Louis Rougier organizó en 1938 en París, con el objetivo de presentar la traducción francesa de The good society, el libro publicado por el periodista Walter Lippmann en 1937. Sin embargo, el estallido de la II Guerra Mundial detuvo, de manera abrupta, las iniciativas surgidas en ese Coloquio, las cuales apuntaban a organizar las diversas líneas de acción y pensamiento "neoliberales” que se habían dado reunión allí (Denord, 2002/5; Peck, 2008; Plewhe, 2009).

Enriquecidas y re-posicionadas estratégicamente durante la contienda bélica, varias de las líneas de renovación del liberalismo que se habían abierto en Alemania, Francia, Suiza, y Estados Unidos, entre otros espacios nacionales, comenzaron a articularse y organizarse tras su finalización. Así, en 1947, bajo el liderazgo de Albert Hunold y Friedrich von Hayek un número importante de intelectuales procedentes de los Estados Unidos y Europa se reunieron en una villa suiza dando nacimiento a la Sociedad Mont Pelèrin $\underline{5}$. Asimismo, los años '50 y '60 fueron momentos de gran activismo para los intelectuales, empresarios, activistas y think-tanks empeñados en la defensa del libre mercado y en el combate contra el comunismo; confrontación esta última que, teniendo en cuenta el contexto de la Guerra Fría, confería a América Latina una particular relevancia.

Promediando la década de 1950 el liberalismo era, en Argentina, una ideología minoritaria asociada con la oposición a la democracia popular (Nallim, 2014:14). Aún sin contar con el apoyo de las masas, tras el derrocamiento de Perón las ideas liberales comenzaron a circular con mayor amplitud: se crearon instituciones y publicaciones especializadas; se constituyeron y/o cimentaron redes de sociabilidad que vinculaban a los liberales vernáculos con intelectuales y núcleos de pensamiento neoliberal de otras latitudes y algunos de los principales exponentes de esas perspectivas visitaron el país ${ }^{6}$.

En diciembre de 1955 se constituyó la Asociación Argentina por la Libertad de la Cultura (en adelante, AALC), la filial argentina del Congreso por la Libertad de la Cultura (en adelante, CLC), el frente cultural pro-occidental creado en 1950 con el propósito de compensar, en el marco de los enfrentamientos políticoideológicos característicos de la Guerra Fría, las intervenciones del sector soviético ${ }^{7}$. Asimismo, un año después daba inicio a su actividad el Foro de la Libre Empresa, entidad que invitó al país a Wilhem Röpke y Albert Hunold, dos prestigios representantes de la renovación del liberalismo europeo.

Reuniendo a representantes de la Sociedad Rural Argentina, La Bolsa de Comercio y la Unión Industrial, en 1958 se estableció la Asociación Coordinadora de Instituciones Empresarias Libres (ACIEL) que, si bien se presentaba como una organización de intereses, mostró un interés creciente en la elaboración y difusión de alternativas teórico-prácticas de orientación neoliberal (Grondona, 2011).

La renovación del campo liberal también vino de la mano de Álvaro Alsogaray, un político y economista que articuló tempranamente en el país el punto de vista de la "economía social de mercado". Vinculado a personalidades que fueron claves para la organización e institucionalización del neoliberalismo, como Walter Erhard, Luigi Einaudi, Friedrich Hayek y Jacques Rueff, en el período que nos ocupa Alsogaray fundó el Instituto de Economía Social de Mercado (1965) y dos partidos políticos de orientación liberal, el Cívico Independiente en 1956 y Nueva Fuerza en 1972 (Llamazares Valduvieco, 1995; Morresi, 2009; Haidar, 2015a). 
Asimismo, ya en los largos años sesenta comenzaron a penetrar en el país las ideas de la moderna "Escuela de Chicago”. En 1961 la Universidad de Cuyo firmó un convenio con la Universidad de Chicago para instrumentar un programa de intercambio académico. Como parte de ese acuerdo que se extendió entre 1962 y 1967, la Agencia Internacional de Cooperación estadounidense otorgó becas a 27 argentinos para estudiar en aquella Universidad del país del norte (Biglaiser, 2002).

Por otro lado, en abril de 1971 empezó a publicarse Política y Economía, una revista creada a partir de la iniciativa de un conjunto de economistas nucleados en torno al Estudio de Rafael Olarra Jiménez y de Carlos García Martínez en la que se pusieron en discusión algunas ideas de aquella última vertiente del neoliberalismo (Odisio y Rougier, 2014).

Próximo a las ideas de la Escuela Austríaca, y, particularmente, al liberalismo "intransigente” (Hayek, 1992 citado por Peck, 2008:8) de Ludwig von Mises, también Alberto Benegas Lynch desarrolló, al igual que los otros actores a los que antes hicimos referencia, iniciativas dirigidas a "revivir", tras el derrocamiento del peronismo, el "espíritu liberal” en la Argentina. Hábil articulador de espacios intelectuales, empresariales y políticos, Benegas se caracterizó, como destaca Martín Vicente (2015), por intervenciones breves y polémicas, marcadas -al igual que aquellas de von Mises- por un estilo doctrinario. Habiendo cursado estudios universitarios en la Facultad de Ciencias Económicas de la Universidad de Buenos Aires, en 1950 viajó a los Estados Unidos donde tomó contacto con von Mises y Hayek, intelectuales que facilitaron su acreditación, en 1957, como miembro de la Sociedad Mont Pelèrin. Su paso por el país del Norte también le permitió estrechar lazos con Ayn Rand, la escritora fundadora de la corriente "libertariana" del neoliberalismo (Morresi, 2011:53), cuyos libros fueron calurosamente promovidos desde las páginas de IsL. Asimismo, en virtud de aquella experiencia conoció a Leonard Read, el carismático presidente de la Cámara de Comercio de Los Ángeles que en 1946 creó la Foundation for Economic Education (en adelante FEE), con la finalidad de "revivir" la filosofía de la libertad.

Todos esos vínculos se consolidarían cuando la Revolución Libertadora lo nombrara consejero de la Embajada Argentina en Washington (Gallo, Cornblit, Rivas et al. 1984) ${ }^{8}$. Fue a partir de esas relaciones y, particularmente, del intercambio con Read, que Benegas Lynch decidió impulsar la constitución, en su país de origen, del CDEL. Como explicaremos en el apartado siguiente, esa institución -cuya creación fuera celebrada por von Mises, Hayek y Read- no sólo encontró inspiración en la FEE, sino que mantuvo, a lo largo del período que aquí estudiamos, un estrecho vínculo con ella.

\section{2.- Educando a las elites para la libertad}

Constituida a partir de una iniciativa de Alberto Benegas Lynch, el CDEL era una usina dedicada a promover y divulgar, en la Argentina, la "filosofía de la libertad”. En ese sentido, además del medio de difusión que constituía IsL, desempeñó un lugar relevante en el desarrollo del mercado editorial argentino dedicado al público liberal. "Predicando entre convencidos" (IsL, 1963:3), la institución se encargó tanto de la publicación de obras dirigidas a audiencias especializadas, como de ensayos y "folletos” que estaban dirigidos a un público más amplio. Considerando en conjunto escritos académicos y populares, entre 1958 y 1975 aparecieron con el sello editorial del CDEL 46 textos. Entre los primeros se incluyen reediciones de “clásicos” del pensamiento liberal, publicaciones de las conferencias que impartieron en Buenos Aires intelectuales y activistas invitados por dicha institución ${ }^{9}$, contribuciones de Alberto Benegas Lynch y otros liberales argentinos, ensayos de Hayek, von Mises y sus discípulos, así como de otros intelectuales miembros de la Sociedad Mont Pelèrin. Además de trabajos científicos y ensayos, en aquel período el CDEL publicó varios "folletos" firmados por Read y otros activistas pertenecientes a la FEE, los cuales apuntaban, en palabras del primero, a “dar claridad” a la explicación de las ideas liberales, formulándolas en lenguaje 
corriente (IsL, 1958:4).

Con sede en la ciudad de Nueva York, la Fundación que dirigía Read era una de las organizaciones más activas en defensa de la ideología de la libre empresa en los Estados Unidos. Financiada por Fundación Volker y empresas como Dupont, General Motors, General Electric y Sun Oil Company, durante la década del '50 orientó sus esfuerzos a desacreditar el liberalismo del New Deal, criticar la legitimidad de los sindicatos y combatir el comunismo. Sin identificarse totalmente con los puntos de vista de los neoliberales, la FEE formaba parte de la comunidad de managers de grandes empresas, periodistas, ejecutivos retirados y, por supuesto, think-tanks, que apoyaban a los pensadores austríacos von Mises y Hayek en Estados Unidos (Phillips-Fein, 2009).

El Centro que dirigía Benegas Lynch mantenía un estrecho vínculo con aquel think-tank. Por un lado, la Fundación dirigida por Read colaboró con el financiamiento y la administración de las becas que el CDEL otorgaba a jóvenes graduados para realizar estudios concernientes a la "filosofía de la libertad" en los Estados Unidos. Fueron dos jóvenes abogados argentinos, Enrique J. Loncán $\underline{10}$ y Eduardo Alejandro Lastra quiénes junto a Gerardo Galván, procedente de Filipinas, obtuvieron, en 1961, las primeras becas $\underline{11}$.

Por otro lado, siguiendo la idea de que "los amigos de la libertad de todo país del mundo...[tenían] la obligación de ayudarse entre sí” (IsL, 1958:4), la FEE suministraba al CDEL gran parte del material que aparecía publicado en IsL, cuya concepción y diseño se había inspirado, a su vez, en The Freeman, la revista de la fundación presidida por Read. Se trataba, en gran medida, de trabajos de escasa densidad teórica, en los que se defendía de manera estridente y radicalizada la libertad de mercado y el individualismo.

Esa estrategia de divulgación, harto simplificada, resultaba complementada con la inclusión en los márgenes de las notas publicadas, de pequeñas "frases" e incluso aforismos de figuras del pensamiento liberal tanto clásico como contemporáneo. A partir del año 1975 esa práctica dio lugar a la organización de una sección específica denominada "Para entrar en materia" que vino a sustituir las editoriales (no firmadas) que principiaban la publicación en las cuales, además de ventilarse asuntos de la vida institucional del CDEL, solían abordarse temas de actualidad.

Paralelamente a esa forma popular de divulgación, IsL contaba con trabajos que denotan mayor profundidad en el tratamiento de los temas. Entre ellos, tenían un lugar destacado los ensayos de autores nacionales que ponían en discusión los temas políticos y económicos de la coyuntura argentina de aquellos años: la integración política de las masas peronistas, la inflación, el tratamiento que debía otorgarse al capital extranjero, la reforma de la Constitución Nacional, la regulación de la actividad sindical, etc.. $\underline{12}$ Así, por ejemplo, en varios de los números de la revista se criticaron las medidas de política económica implementadas por los elencos gubernamentales que se sucedieron entre 1958 y 1975. Sin embargo, la aproximación a esos temas de actualidad estaba siempre mediada por la referencia a los valores, grandes principios e instituciones del liberalismo. Ese estilo "doctrinario" permitía que el grupo de ideas que constituía el CDEL se auto-presentara como un espacio de pensamiento independiente, tanto del campo de los negocios como de la política. En esa dirección, y con la finalidad de evitar que se identificara la defensa de la economía libre con el interés empresario, es que en 1959 la organización decidió cambiar de nombre, pasando de llamarse "Centro de Difusión de la Economía Libre" a denominarse "Centro de Estudios sobre la Libertad” (IsL, 1959: 3). Asimismo, en una maniobra de distanciamiento respecto del campo político, en 1962 las páginas de IsL comunicaban la creación de una nueva entidad, el “Club de la Libertad”, que tenía por finalidad defender, en el terreno político, las mismas ideas que el CDEL promovía en un nivel “intelectual” (IsL, 1964:2) ${ }^{13}$.

Considerado globalmente, el esfuerzo editorial que la revista trasuntaba respondía a dos convicciones 
simultáneas: era necesario dar la batalla contra el comunismo en el plano de las ideas, y la misma debía librarse entre las capas dirigentes de la sociedad.

Al difundir los materiales procedentes de la FEE, no menos que las intervenciones de los ensayistas nacionales, IsL cumplía cabalmente con la misión que Hayek (1949) había encomendado a los intelectuales de la derecha liberal en un paper puesto en circulación en el ámbito de la Sociedad Mont Pelèrin: actuar como distribuidores de "segunda mano" de las ideas liberales. De allí que la revista se auto-presentara, en sus editoriales, como un medio dedicado a aumentar la eficacia de la lucha contra el colectivismo, poniendo a disposición de las elites toda la literatura y los medios de difusión que estaban a su alcance (IsL, 1961:4; IsL, 1964:3).

Benegas Lynch (1963:34) era de la idea de que, en el largo plazo, el triunfo de la causa liberal sólo podía lograrse a través del cambio en las corrientes de opinión. De ahí que, sin subestimar la acción militar de los Estados Unidos en la lucha contra el comunismo, se encargó de poner de resalto, en varias contribuciones, la fragilidad e incluso el carácter "pírrico" de victorias bélicas conseguidas en un contexto general de derrota cultural para el proyecto liberal, atribuyendo a la disputa ideológica sino un papel sustitutivo, al menos “complementario" de las lucha a través de las armas.

Para revertir la orientación colectivista que, bajo el "influjo del pensamiento de Marx" (IsL, 1961:2) asumían las masas, era preciso actuar "de arriba hacia abajo", formando a los “conductores” en la filosofía de la libertad. Esta opción por las élites encontraba, en la revista que estamos analizando, varios puntos de apoyo.

Floreal González (1969:21), integrante de la comisión de publicaciones del CDEL, hacía funcionar esa preferencia como declinación de la oposición jerarquizada que el liberalismo establece entre los valores de la "libertad” y la "igualdad”. “Comencemos por aclarar [decía]...que los liberales anteponemos las élites a las masas, por la misma razón que preferimos la libertad a la igualdad”. Por su parte, en la prosa versada del empresario cordobés Manuel Tagle (1959:6), a la sazón, vocal del Consejo de Administración del CDEL, la preferencia hacia "los mejores" se vinculaba tanto con el peligro, histórico, que para los liberales encarnaban las mayorías, como con los efectos corrosivos que tenía, desde ese punto de vista, el igualitarismo.

Por otra parte, en torno de esa opción por las élites rondaba la idea de que la crisis que padecía, desde 1930, la democracia liberal, era una “crisis de conducción”. Movilizada para comprender la situación política argentina, esa interpretación resultó apuntalada por una de las lecturas del peronismo que, habiendo cosechado gran número de adeptos tras el golpe de 1955, entendía que el mismo se había fundado en el “engaño de las masas” perpetrado por un líder demagógico $\underline{14}$.

Con todo, cuando en las vísperas de la clausura de la experiencia, fracasada, de la "Revolución Argentina” y del probable regreso al centro de la escena política argentina del ex presidente Perón, Tagle (1972:13) advertía acerca de la actuación demagógica de "titiriteros expertos" en las "llamadas" revoluciones populares, no sólo mostraba el desprecio que los intelectuales liberal-conservadores argentinos sentían respecto de los populismos. Esa opinión expresaba, también, la profunda desconfianza que suscitaban los liderazgos políticos en distintas vertientes liberales, de la cual daban testimonio las "frases" de "hombres eminentes” del liberalismo francés y argentino del siglo XIX, con las que los responsables de IsL poblaban los márgenes de las notas publicadas.

Tomando distancia tanto respecto de las masas como de los líderes, el desafío de la revista que estamos analizando consistía en apostar a la formación de élites que fueran capaces de engendrar, en las masas, “creencias liberales”. Ese proyecto, aun apadrinado por Hayek, no dejaba de engendrar cierta contradicción con la concepción limitada, fragmentaria y dispersa del conocimiento humano que el mismo defendía, según la cual ningún sujeto (un partido, una comisión de expertos, etc.) podía arrogarse la capacidad de incidir sobre el rumbo de la sociedad considerada como un "todo" (Denord, 2009). 
También algunos de los “distribuidores de segunda mano de ideas”, con los que Hayek contaba para enraizar -en una estrategia de largo plazo- las ideas neoliberales, compartían con el autor de Camino hacia la servidumbre la desconfianza respecto de la posibilidad de que ciertos hombres y grupos fueran capaces de orientar los destinos colectivos, aplicando alguna forma de conocimiento al "gobierno" de la sociedad. Así, tras criticar, en un trabajo publicado en IsL, el "colectivismo político”, modelo que remitía a un estar "todos amontonados en una masa humana”, Leonard Read (1959:13) se sintió en la necesidad de incluir la siguiente aclaración: "Esta baja idea del colectivismo político no debe tomarse erróneamente como un arrevesado [sic] endoso de la idea del 'rey filósofo' de Platón, y de su réplica moderna: la sociedad debe ser totalmente gobernada por comisiones de la élite creadora”.

Sin embargo, la sospecha que recaía sobre el conocimiento experto no impidió que la FEE y el CDEL, entre otras instituciones, se embarcaran, durante el período de la Guerra Fría, en la "batallas de las ideas”, lo cual permite vislumbrar una de las múltiples tensiones que atraviesan el proyecto neoliberal $\frac{15}{}$, con el cual el CDEL mantenía, como explicaremos en el apartado siguiente, una relación ambivalente.

\section{3.- Una relación ambivalente con el proyecto neoliberal}

Tal como explicamos sucintamente en el apartado 1, el neoliberalismo emergió hacia los años '30 como respuesta reconstructiva frente a la crisis en la que estaba sumido el liberalismo, configurándose en las décadas subsiguientes a partir de la construcción de un campo de adversidad (Foucault, 2012) conformado tanto por las filosofías socialistas de la planificación, como por liberalismo del “laissez-faire”. Así, uno de los rasgos que caracterizan y justifican el sufijo "neo” de su denominación, es que supuso una operación de revisión y renovación del liberalismo clásico, particularmente en lo que respecta a la concepción del

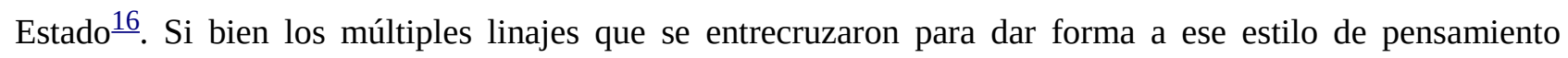
colectivo (así, el ordoliberalismo, la Escuela de Chicago, etc.) presentan importantes divergencias en relación a aquel tópico (entre otros aspectos), un rasgo en común estuvo dado por el esfuerzo por re-problematizar el límite entre el “Estado” y el “mercado”. Así, la pretensión de delinear -tras la crisis económica de 1930 y la experiencia de los fascismos- una racionalidad adecuada para el capitalismo, condujo a los neoliberales a plantearse la cuestión de la función “positiva” que el Estado debía desempeñar para garantizar un orden competitivo, el cual se pensaba como condición para la libertad individual.

Pues bien, teniendo en cuenta ese doble registro de confrontación, dado, simultáneamente, por la crítica a las filosofías socialistas de la planificación y la discusión del liberalismo clásico, la participación que IsL tuvo en el proyecto neoliberal puede caracterizarse como "ambivalente".

Ello es así porque, fuertemente marcada por la impronta de von Mises, quién cultivaba, al interior de ese

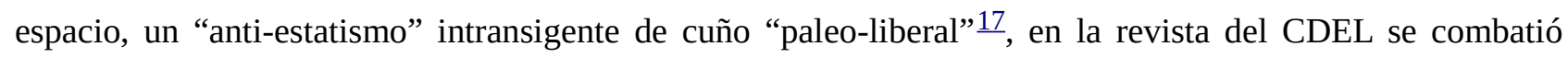
incansablemente el "colectivismo”, pero, al mismo tiempo, se reafirmó y exaltó la tradición liberal argentina. A esta operación de recuperación de la tradición nos referiremos en el apartado siguiente. Antes, conviene profundizar en torno al modo cómo IsL construyó su propio “discurso adversativo” (Verón, 1996).

El enemigo omni-presente, despreciado y envidiado a la vez era el comunismo, cuya doctrina Benegas Lynch (1963:38) convocaba a desentrañar leyendo a sus más destacados ideólogos: Marx y Engels. Sin embargo la hipótesis del "totalitarismo económico", sostenida por Hayek, como el virulento anti-estatismo de von Mises constituyeron, en la revista que estamos analizando, las fuentes de una pulsión orientada a desenmascarar a los adversarios que se escondían detrás de las propias ideas liberales.

La precisión terminológica era necesaria, en el entendimiento de los responsables de IsL, para esa operación de desvelamiento. Considerando que gran parte de las contribuciones que se publicaban eran piezas de la 
"lucha por las ideas" que la FEE, entre otros actores, estaba dando, en los Estados Unidos, contra distintas expresiones del liberalismo social, la Redacción solía introducir notas a pie de páginas destinadas a advertir al lector argentino que el término "liberal” identificaba en aquel país del norte al "progresismo de izquierda". Teniendo presente esa posibilidad de confusión, Benegas Lynch solía aclarar, asimismo, en sus ensayos, que asignaba a la palabra "liberal” el sentido que se le atribuía, en el siglo XIX, en los países de Europa continental.

Por otra parte, también el término "neoliberalismo” -que ni Benegas Lynch ni otros ensayistas que formaban parte del grupo de ideas del CDEL utilizaban- aparecía como una arena de disputas al interior del propio campo liberal. Resulta significativo que a propósito de un artículo de Hayek, publicado en el primer número de la revista, la Redacción advirtiese que el autor empleaba el significante "neoliberalismo” para designar "el nuevo renacer del pensamiento a favor de la libertad” y no con la acepción que a esa palabra daban en la Argentina "algunos que pregonan como neo-liberalismo un sistema de ideas, que concede tanta acción a la intervención del Estado, que su doctrina se parece más a un socialismo atemperado que a la tesis de la libertad (“Nota de redacción” en Hayek, 1958:16).

Tomando distancia respecto de aquellos economistas liberales que, como Álvaro Alsogaray (1968:37), admitían la aplicación de medidas proteccionistas en las fases incipientes de la industrialización, la aclaración de la Redacción se explica por la adhesión incondicional del CDEL a la ortodoxia que representaba la "moderna escuela vienesa” (IsL, 1962:2), una de las alas más radicales e intransigentes de la derecha liberal, encarnada por von Mises y sus discípulos; que contaba, en los Estados Unidos, con el apoyo del grupo de empresarios y de think-tanks conservadores. Ciertamente, las ideas de la "praxeología” $\underline{18}$ ocupaban un lugar destacado en IsL: allí se publicaban, en forma asidua, artículos del economista austríaco y de intelectuales que formaban parte de su círculo de ideas, así como reseñas de sus libros $\underline{19}$; sin perjuicio de que sus ideas (como por ejemplo la polémica propuesta de retornar al "patrón oro") eran calurosamente promovidas en los ensayos de Benegas Lynch.

Lejos de reducirse a un problema terminológico, la vocación por definir el “auténtico liberalismo” condujo a organizaciones como la FEE y el CDEL -defensoras intransigentes del sistema de libre mercado- a disputar a otros espacios el sentido de términos y valores caros al linaje liberal, por caso la "libertad".

De una disputa de ese estilo da cuenta, por ejemplo, el empleo, como signo de una identidad compartida, de la expresión "amigos de la libertad” (IsL, 1958), en el intercambio epistolar que el CDEL mantuvo con la fundación dirigida por L. Read en ocasión de su constitución.

Aquella fórmula venía siendo utilizada desde comienzos de los '50 en el marco del entramado institucional conformado alrededor del CLC. Así, la "Asociación francesa de los amigos de la libertad”, creada en dicho país de Europa bajo el auspicio del CLC, así como la asociación “Jóvenes amigos de la Libertad”, originada a partir de la primera (Jannello, 2012b), portaban dicha expresión en sus respectivas denominaciones.

Ciertamente, el CDEL -al igual que la FEE- compartía con el CLC la misión de custodiar y reanimar, en la coyuntura particular de la Guerra Fría, el valor de la libertad, así como de combatir las ideas de cuño totalitario. Sin embargo, ambas entidades diferían en varios aspectos.

Mientras la asociación que impulsara Benegas Lynch en la Argentina comulgaba con las ideas "paleoliberales” de von Mises, la orientación ideológica del CLC era más plural, abarcando un arco que iba desde la izquierda más antistalinista (comunistas desilusionados, anarquistas, trotskistas y socialistas) hasta el liberalismo conservador, pasando por el liberalismo progresista (Jannello, 2012b).

De esa pluralidad daba cuenta, también, la filial argentina del CLC. Creada en 1956, la AALC estaba integrada por políticos e intelectuales que “cubrían prácticamente todos los sectores legitimantes dentro del 
campo de la cultura como universidades, medios de comunicación, sociedades intelectuales, gestión de gobierno y tendencias políticas” (Jannello, 2015: 29). Entre ellos había radicales, liberales laicos, demócrata progresistas, académicos e intelectuales independientes pero, por su número y actividad, un peso significativo lo tenían los militantes y simpatizantes del Partido Socialista (Bozza, 2009).

Asimismo, al tiempo que las páginas de IsL se hacían eco de las posturas anti-comunistas procedentes de los sectores más reaccionarios de los Estados Unidos, el discurso anticomunista del CLC pretendía ser “progresista, democrático e independiente de la influencia de las grandes potencias” (Jannello, 2015:19)

Por otro lado, mientras el CLC funcionó como un espacio de promoción de la libertad de pensamiento en oposición a la censura y el totalitarismo de corte comunista (particularmente el soviético), el activismo del CDEL se concentraba, al igual que el de la FEE, en torno a la exaltación del valor de la competencia; la defensa del derecho de propiedad y de las libertades económicas.

La importancia que estos aspectos tenían en la prédica del CDEL resulta comprensible si consideramos que su fundador, A. Benegas Lynch, procedía del mundo empresarial, no menos que Manuel Tagle, otra de las voces de peso entre aquellas que orbitaban alrededor del CDEL. Pero, asimismo, el énfasis sobre las libertades económicas se explica porque, sin subestimar la importancia de la dimensión ética de la libertad (y de derechos tales como la libertad de expresión), Benegas Lynch convergía con Hayek en pensar que el mercado funcionaba como "garantía" frente a la tendencia a la concentración de poderes en manos del Estado.

En sintonía con Hayek, Benegas Lynch (1960, 1963b) entendía que el programa de la libertad constituía un todo indivisible, cuyas partes estaban condicionadas las unas a las otras, por lo que si declinaba la propiedad recaían las otras libertades. Esa posición lo alejaba tanto de las fórmulas de la "tercera vía” que, al interior del campo neoliberal, encarnara la "economía social de mercado” preconizada desde Alemania por MüllerArmack y defendida en Argentina por Álvaro Alsogaray, como de la lectura en clave ética del liberalismo propuesta por Croce (1952), que restaba centralidad a los principios económicos y lo disociaba del sistema de la libre competencia, interpretación que, en Argentina, encontraría asidero en las elaboraciones del dirigente socialista A. Ghioldi (Martínez Mazzola, 2011a).

Así, con la finalidad de advertir a los propios del peligro de restringir la libertad económica, el presidente del CDEL utilizaba El Manifiesto Comunista (como una suerte de weberiano "tipo ideal” de economía socialista) para evaluar el grado en el que distintas medidas de política económica se aproximaban al comunismo. Desde este punto de vista caían fuera del campo liberal las decisiones gubernamentales que consentían, aun por razones pragmáticas, que el Estado avanzara sobre el mercado; no menos que todas aquellas intervenciones que apuntaban a la distribución de la riqueza y/o a la protección social de los asalariados.

En relación a esta última cuestión, IsL es un excelente muestrario de las críticas que los intelectuales y activistas conservadores de la libertad de mercado esgrimían, en los Estados Unidos, contra los sindicatos, la jurisprudencia progresista que avanza en la regulación de las relaciones laborales y los proyectos de seguro social. Mientras los sindicatos encarnaban, para los estadounidenses, buena parte de las amenazas a la libertad de empresa, los obstáculos al mercado residían, en la opinión de los liberales argentinos, en una trama de regulaciones, agentes, instituciones y actitudes que, forjada al calor del peronismo, parecía más compleja y difícil de desarticular.

Tras largos años de “tiranía” (Benegas Lynch, 1964:18), los empresarios locales padecían, entre otras cosas, el "desmesurado poder de las organizaciones obreras” (Smith, 1963:33) y un régimen jubilatorio “monstruoso" (Tagle, 1964). Con diferentes argumentos, la ofensiva ensayada desde IsL contra las políticas que apuntaban a combatir la desigualdad social fue intensa. No faltaron las voces que exaltaban la "utilidad" del individualismo y de la desigualdad social ni las que avanzaban en la apología del american way of life ${ }^{\underline{20}}$. 
En todo caso, la retórica reaccionaria enfocada hacia los problemas nacionales se fue modulando según las distintas configuraciones que entre 1958 y 1975, asumieron las “tendencias antiliberales”. Así, por ejemplo, la circulación, durante el gobierno del general Juan C. Onganía (1966-1970) de discursos corporativistas, permite entender la presencia, en los trabajos publicados por aquellos años, de formulaciones que apuntaban a aclarar que la sociedad estaba compuesta por "personas" (González,1969) y, que, como tal, carecía de intereses o fines propios (Benegas, 1970).

Uno de los focos más destacados de las querellas anti-colectivistas está dado por las teorías, estrategias e instituciones que formaron parte, en el periodo que analizamos, de la problematización del “desarrollo”. Así, las páginas de IsL refractaron las críticas que los intelectuales y activistas del ala más radical de la derecha liberal estadounidense, pero también latinoamericana, dirigieron tanto a los enfoques de la "economía del desarrollo" como a la política internacional de "ayuda al desarrollo" implementada por el gobierno de los Estados Unidos, la cual, en el caso de América Latina, se enmarcó en la denominada “Alianza para el Progreso". Las controversias, que se desplegaron en distintos espacios, suponían el cuestionamiento técnicoeconómico de la orientación intervencionista e industrialista que, a partir de las recomendaciones de los expertos de Naciones Unidas o del propio gobierno estadounidense, asumían las políticas económicas en los países beneficiados por los programas de ayuda al desarrollo. Pero, más frecuentemente, la reprobación que esa clase de estrategias se basaba en razones geopolíticas y/o en un conjunto de motivos sociológicos y culturales asociados al discurso colonialista.

Uno de los autores que más se ocupó de combatir tal clase de programas fue el economista Hans Sennholz. Discípulo de von Mises, en las notas publicadas en IsL el ex piloto de la Lufwaffe ${ }^{21}$ advertía respecto del peligroso "anti-occidentalismo" que exhibían los países subdesarrollados a los que se dirigía la ayuda de los países centrales (Sennholz, 1959), sosteniendo, asimismo, que la misma -lejos de crear las condiciones para el libre mercado-, fomentaba el "estatismo y el socialismo" (Sennholz, 1962: 25), opinión que también compartía el periodista y militante de las ideas de von Mises, Henry Hazlitt (1967).

Pero esa clase de preocupaciones no era privativa de la derecha liberal estadounidense. Los intelectuales y activistas latinoamericanos comprometidos con la causa del mercado se expresaron críticamente en una dirección semejante. Así, uno de los pocos latinoamericanos que integraban la Sociedad Mont Pelèrin, el abogado mexicano Gustavo Velasco (1959:25), se lamentaba, en un discurso impartido en una de las reuniones de aquella Sociedad, del sesgo antiliberal que asumían las recomendaciones para el "desarrollo" que los técnicos de los países centrales impartían a sus colegas latinoamericanos y exhortaba a las naciones adelantadas a "dar el buen ejemplo".

Asimismo, los ecos que, a través de IsL, nos llegan de la polémica que suscitó, tanto en los Estados Unidos, como en los foros transnacionales de discusión de ideas neoliberales, la cuestión de la "ayuda al desarrollo", permiten reconstruir los argumentos que los economistas y activistas de los países del Norte que estaban a favor de la libertad de mercado, movilizaban para negar a los países periféricos la posibilidad de industrializarse. Una buena muestra del repertorio de motivos anti-industrialista se encuentra en el artículo titulado “La Alianza para el Progreso tiene que fracasar”, publicado en el № 19 de IsL. Allí un especialista en investigaciones de mercado residente en México enumeraba los obstáculos con los que los proyectos industrialistas se topaban en los países latinoamericanos: empleados públicos incompetentes y corrompidos, falta de una tradición republicana representativa, abultada burocracia, desventajas económicas relativas a la escala económica, los costos comparativos y la especialización de recursos (Fox, 1964).

A esos factores político-institucionales y económicos, Sennholz sumaba una serie de motivos culturales. El error fundamental en el que incurrían el presidente Kennedy y sus consejeros residía, para el discípulo de von Mises, en una equivocada apreciación acerca de la causa de la riqueza y la productividad, la cual demandaba ciertos "prerrequisitos” intelectuales, políticos y sociológicos (tales como el "espíritu de 
trabajo”) que estaban presentes en los países más ricos y ausentes en las regiones subdesarrolladas, y que no podían exportarse o crearse "de la noche a la mañana" porque eran el producto de siglos de "pensamiento ético y praxeológico” (Sennholz, 1963:24).

Tampoco los becarios del CDEL que habían cursado estudios en los Estados Unidos se privaron de expresar sus opiniones en los debates en torno del desarrollo. Así, en una conferencia impartida en la "American Association" de Montevideo, Loncan se refirió al espinoso problema de las estrategias de capitalización a partir de las cuales los países periféricos, y entre ellos la Argentina, conseguirían desarrollarse. Consideraba que la idea (sostenida, entre otros, por la CEPAL) de restringir, mediante la intervención del Estado, los hábitos de consumo de las clases altas, de manera de redirigir el ingreso hacia la capitalización, era un “esfuerzo intolerable desde el punto de vista político y social” (Loncan, 1975:10) e insistía, como otros autores del CDEL, en que la capitalización dependería de la inversión de capitales extranjeros.

Por su parte, en un trabajo publicado en 1966 que llevaba por título la curiosa expresión “¿Es eso Desarrollo?”, Fernando Benegas se ocupó de articular el punto de vista de la Escuela Austríaca en los debates acerca del desarrollo argentino. Fundado en la teoría subjetiva del valor formulada por Carl Menger, uno de los precursores de aquella Escuela, en 1871, el artículo estaba consagrado, en su médula, a negar la posibilidad de que pudiera articularse algún punto de vista colectivo acerca del desarrollo, puesto que, en palabras del autor "lo que antes se llamaba progreso", se definía subjetivamente, siendo lo que "cada uno individuamente experimenta de acuerdo con sus propias valoraciones” (Benegas, 1966: 47).

Ahora bien, independientemente de esas opiniones, como del propio "auto de fe” que el CDEL había hecho en favor de la Escuela Austríaca, gran parte de la labor de reactivación de la filosofía de la libertad que dicha institución emprendió consistió, como veremos en el apartado siguiente, en la afirmación y divulgación de valores y creencias muy generales plasmados en la tradición liberal argentina.

\section{4.- La reactivación de la tradición liberal argentina}

Más allá de la importancia que en IsL se otorgaba, como vimos en el punto anterior, a la "crítica”, Benegas Lynch (1960:16) tenía consciencia de que, para combatir el colectivismo, era necesario contar con una "filosofía propia de la vida social", clara y contundentemente opuesta a la doctrina que emanaba del Manifiesto Comunista. Nada le pareció más seguro, para lograr ese propósito, que "retornar la tradición argentina” (1960:16).

Constituida a lo largo del siglo XIX y la primera década del XX a partir de la yuxtaposición y el entrecruzamiento de diferentes vertientes de pensamiento liberal, diseños institucionales y prácticas políticas, "la” tradición liberal argentina sobre la que los hombres del CDEL depositaron sus esperanzas era tan heterogénea como, promediando el siglo XX, el proyecto neoliberal. Sin embargo, en las páginas de IsL el “pensamiento de Mayo”, las ideas de la denominada “Generación del '37” y la Constitución Nacional de 1853, se pusieron en movimiento como si constituyeran un cuerpo unificado, una doctrina coherente.

Así, los responsables de IsL manipularon los Escritos Económicos de Manuel Belgrano, el Sistema Económico y Rentístico de la Confederación Argentina de Juan Bautista Alberdi y la Historia de Belgrano y la Independencia Argentina de Bartolomé Mitre, entre otros textos del liberalismo argentino del siglo XIX, con la sutilidad y paciencia de un bricoleur. Tomaban frases de esas obras y las colocaban en el centro de las contratapas de los diferentes números, haciéndolas funcionar a la manera de “colofón”, o bien las disponían en los márgenes de las notas. Asimismo, seleccionaban y organizaban fragmentos con los que componían pequeños textos que aparecían publicados en una sección denominada Verdades Eternas. A estas modalidades, a partir de las cuales los discursos (plurales) del liberalismo del siglo XIX fueron “reactivados”, es preciso agregar las frecuentes referencias que en las contribuciones de autores argentinos se 
hacía a la Constitución Nacional de 1853.

En este último documento, que había proveído el andamiaje jurídico-institucional para el nuevo Estado republicano-liberal imaginado por los intelectuales de la Generación de 1837, residía, según la interpretación de Benegas Lynch (1971:45), el "fundamento racional” de la sociedad argentina, el cual había asegurado el "progreso" del país: la libertad individual, la propiedad privada y un sistema democrático de gobierno con funciones limitadas a la protección de esos valores.

Esa representación "modélica” de la Constitución Nacional, introducida por el presidente del CDEL en una exposición que databa de 1967, y cuya síntesis apareciera en un libro publicado, en 1971, en homenaje a Federico Pinedo, da cuenta del modo en que concebía al liberalismo: esto es, como una doctrina única, coherente y homogénea que se había mantenido incólume desde sus orígenes en el siglo XVII en Europa hasta su consagración como ideología en el siglo XIX.

De la mano de lecturas como la propuesta por Benegas Lynch quedaban obliteradas las diferencias entre las corrientes que configuraron la historia del liberalismo argentino a lo largo de los siglos XIX $\underline{22}$ y XX, no menos que las múltiples recepciones e interpretaciones de las que fuera objeto la tradición liberal argentina en diferentes períodos históricos.

Así, a lo largo de las décadas del '30 y del '40 la misma funcionó como una suerte de plataforma valorativa común para el frente antifascista que integraron, intelectuales y políticos conservadores, radicales, demócrata progresistas, anarquistas, socialistas y comunistas $\underline{23}$.

En esa dirección, entre otros elementos de aquella tradición que fueron rescatados en el marco de la apelación antifascista (Bisso, 2007), estaba la Constitución Nacional de 1853, la cual había sido calificada, con bastante anterioridad a que Benegas Lynch desarrollara su panegírico sobre ella, como "Palladium” de la libertad. El elogio, consonante con una interpretación en clave "ética" del liberalismo que hacía de la libertad el motor de la historia argentina, había sido proferido por el socialista Américo Ghioldi $\underline{24}$, intelectual que, además de subrayar el valor de la Constitución, se ocupó de resaltar las aristas pedagógicas del pensamiento de Sarmiento (Viana, 2009; Martínez Mazzola, 2011a).

Antiguo dirigente del partido socialista, tras su escisión en 1958, Ghioldi quedó al frente del Partido Socialista Democrático $\stackrel{25}{ }$, la fracción que encarnaba la "línea liberal” dentro del socialismo (Tortti, 2016) y que, en el contexto post-peronista, continuaba celebrando la tradición liberal, en el entendimiento de que la misma representaba la continuidad de una corriente en la que se había cifrado el progreso argentino (Martínez Mazzola, 2011a).

Ciertamente, los distintos posicionamientos asumidos, tras la Revolución Libertadora, frente a la cuestión peronista, hicieron que el frente antifascista perdiera su eficacia como herramienta política, generando distanciamientos entre aquellos intelectuales que, como los miembros del CDEL y el socialista liberal Américo Ghioldi (entre otros), desconfiaban profundamente del populismo $\underline{26}$ y aquellos que, sin renunciar totalmente al "pasado liberal”, manifestaron una creciente sensibilidad hacia lo "nacional-popular".

Tal fue el caso del intelectual comunista Héctor P. Agosti. Interpelado por la experiencia peronista, no menos que por el discurso antiimperialista y la crítica antiburguesa que caracterizaron la retórica comunista soviética de la Guerra Fría, Agosti -por entonces la figura intelectual más importante del comunismo argentino- se abocó a reconsiderar la herencia de Mayo, tarea que incluyó el esfuerzo por imprimirle un acento tanto "antiimperialista”, como "popular y democrático", que permitiera diferenciar la apropiación comunista de aquella puramente liberal (Petra, 2013a:289-297)르.

Como se señala en varios estudios (Cattaruzza, 2007; Pasolini, 2005, 2013; Petra, 2010, 2013a, 2013b), la 
herencia liberal formaba parte, ya desde mediados de la década del '30, de la identidad política de los comunistas, quiénes -no sin conflictos y matices- reivindicaban la Revolución de Mayo y el proyecto fundador de la generación del '37, considerándolos como el punto de partida para la promesa revolucionaria futura $\underline{28}$.

Así como los comunistas engarzaron las aristas democrático-progresistas del liberalismo argentino del siglo XIX en un programa político orientado hacia el futuro, también el uso que hombres del CDEL hicieron de él estaba justificado por el deseo de modelar el porvenir de la nación, si bien en un sentido que, como explicamos más abajo, tendía a reforzar las dimensiones conservadoras y elitistas de aquella tradición.

Es que, con sus próceres, sus fórmulas canónicas, emblemas y rituales, la tradición liberal argentina constituía para estos últimos aquello por lo que Hayek venía batallando desde la constitución de la Sociedad Mont Pelèrin: una "utopía liberal" disponible. Frente al lenguaje técnico y a la propensión a los cálculos matemáticos que caracterizaban a la economía del desarrollo, aquella ofrecía una retórica saturada de atractivas fórmulas. El "milagro argentino" (González, 1973:34) y los “progresos explosivos” (Benegas Lynch, 1963b:11) que los autores atribuían a la llamada Generación del '80 evocaban, así, la memoria de un pasado glorioso, cuya dinámica, truncada por el peronismo, era factible recrear, siempre y cuando las clases dirigentes acertaran en "aplicar” la doctrina liberal condensada en la Constitución del '53, a la "realidad nacional”.

Convocados para apuntalar y legitimar la tesis de que la filosofía "propia” de la vida social argentina estaba compuesta por los valores y principios que definían la doctrina liberal, los discursos del liberalismo del siglo XIX, lejos de representar una huída hacia el pasado (Heredia, 2002) se integraron a los debates que jalonaron la actualidad nacional entre la aparición del primer número de IsL, en 1958 y fines de 1975, y ello con varios propósitos.

Por un lado se trató de resaltar la idea de que la defensa de la libertad económica había funcionado, en el contexto de la Revolución de Mayo de 1810, como condición para la independencia política. En esta dirección, en un trabajo publicado al tiempo del derrocamiento del peronismo, Benegas Lynch (1960) comparaba, mediante una apelación metafórica, a los hombres de Mayo con su propia generación, para sostener que la libertad contra el intervencionismo y el dirigismo económico había sido el "ariete explicativo" del quiebre político de 1810. Cristalizado en la Constitución de 1853 y negado por el peronismo, para prevenirse del colectivismo la Revolución Libertadora debía restituir ese ideario, “retornando" a la tradición nacional (Vicente, 2013a).

También la publicación de fragmentos escogidos de la Historia de Belgrano y de la independencia argentina se utilizó para ensayar una interpretación semejante. Un comentario introducido por la Redacción a modo de prólogo comunica el porqué de la publicación de un fragmento de la obra de Mitre que evoca un cuadro que preludia la Revolución de Mayo.

El virrey Cisneros, que se había hecho cargo del gobierno el día 30 de junio de 1809 (...) tuvo que ceder a la presión de los acontecimientos y aceptó la implantación de la libertad de comercio que los criollos exigían, la cual sirvió sin duda alguna de sustento material para la emancipación política proclamada pocos meses después, el 25 de mayo de 1810 (Mitre, 1975:57).

Así, la situación a la que se alude funge, para los responsables de IsL, como “antecedente histórico” de que la libertad económica, había sido conquistada, en el Río de la Plata, “antes” que la libertad política.

Entre estas prácticas de lectura, que apuntaba a visibilizar la convergencia entre la "doctrina económica” de la generación de Mayo y aquella defendida desde el CDEL, Benegas Lynch (1960:12) no se privó de atribuir 
a Manuel Belgrano el arte de "anticipar” los “postulados básicos” de la teoría subjetiva del valor formulada por Menger hacia fines del siglo XIX, sobre la cual se asienta la praxeología de von Mises.

Por otro lado, los intelectuales argentinos que publicaban en IsL retomaron los documentos del liberalismo argentino del siglo XIX con la finalidad de reforzar la concepción elitista y "moderatista" de democracia (Vidente, 2015) hacia la cual se sentían inclinados. Deseosos de encauzar el problema, abierto tras el golpe de Estado de 1955, de la integración de las masas al sistema político por carriles que aventaran el peligro de una recaída en el populismo, recuperaron, de la tradición liberal fundacional, aquellas formulaciones que justificaban la exclusión temporaria de la ciudadanía política de los individuos que, en la representación de esas elites, carecían de cultura política para participar en forma inmediata de la cosa pública (Morresi, 2010:106).

En este sentido, Tagle, vocal del Consejo de Administración del CDEL, encontró en la noción de ciudadanía política delineada por Esteban Echeverría un buen argumento para justificar la proscripción que pesó sobre el peronismo entre 1955 y 1973. Al igual que los liberales doctrinarios franceses del siglo XIX, el autor del Dogma Socialista entendía la ciudadanía como un proceso gradual e histórico que, abierto en el caso de la Argentina en 1810 con el reconocimiento de la soberanía del pueblo, debía dar lugar a la conformación de una elite capacitada para el ejercicio del gobierno sostenida en el concepto de "soberanía de la razón”. Es que en el paradigma elaborado, entre otros, por Guizot, el poder político pertenecía quiénes podían actuar según la “razón”, es decir, a los “ciudadanos capacitados” (Palti 1994/1995, Betria, 2012). Como “magnífico profeta” (Tagle, 1959:8), Echeverría había previsto los peligros de derivados de la manipulación demagógica de las masas "no preparadas". La repetición, a lo largo de la historia argentina, de líderes autoritarios encumbrados en virtud de la falta de independencia y de instrucción de las masas, aconsejaba, entonces, excluirlas temporariamente del cuerpo político $\underline{\underline{29}}$.

Las restricciones al derecho de sufragio, defendidas desde IsL, cuajaban con el lugar subordinado que, desde el mismo espacio, se le otorgaba a la democracia en relación con la república, figura que condensaba los valores de la propiedad privada, la libertad negativa, la limitación del poder del Estado y el Occidente cristiano. Este último tópico se transformó, en el contexto de la Guerra Fría, en una clave analítica para las fuerzas liberales, que lo utilizaban para condenar a las expresiones que resultan distorsivas de la propia cultura occidental, como el marxismo, el humanismo ateo o el populismo (Vicente, 2015:182).

El hecho de que la libertad individual y la propiedad privada se concibieran como los valores pilares de la civilización occidental y cristiana permite comprender porqué para este grupo de ideas, la "desoccidentalización” equivalía, en lo esencial, a la “desliberalización” (Abdala, 1961:59). Lo que estaba en juego, según lo indicara claramente Abdala, un periodista virulentamente antiperonista, era el "estilo de vida” occidental, el cual se nutría en una “concepción casi religiosa de la libertad individual” (1961:59).

También la lectura que subordinaba la democracia a los valores de la república se inscribía, al igual que la doctrina económica del libre mercado, en la Constitución Nacional de 1853, a la cual funcionaba, en la representación de aquellos hombres, como una “figura totémica” (Vicente, 2015:177). Según explicara Benegas Lynch (1971:65) en un libro realizado en homenaje al economista Federico Pinedo, aun cuando la Constitución hacía referencia a los derechos políticos, las libertades civiles eran las que constituían, sin lugar a dudas, la "sustancia de todo el sistema de la Constitución en sus aspectos institucional, político, económico y financiero”. Claramente, para los intelectuales vinculados a la usina de divulgación de ideas creada por A. Benegas Lynch, los primeros no tenían el mismo valor que las segundas. Mientras las libertades civiles se reputaban como los "auténticos" derechos, la valencia de las libertades políticas era relativa y variable. Llegado el caso de una "trágica disyuntiva entre ambos” (Sánchez Sañudo, 1965:42) la solución residía en sacrificar los derechos políticos, imponiendo “proscripciones” cuya aceptabilidad reposaba en la defensa del 
modo de vida liberal (Haidar, 2016a).

Ciertamente, esta relativización de los denominados “derechos de participación” no significaba un rechazo total de la democracia, sino que, más bien, expresaba las limitaciones que el liberalismo conservador encontraba en sus formas populares y masivas. Sin embargo, aun cuando desde el CDEL se abonaba la fórmula de la democracia liberal, no faltan, en IsL, intervenciones dirigidas a justificar los golpes de Estado. Así, en agosto de 1962, a poco de acaecido el golpe que derrocara al presidente desarrollista Arturo Frondizi, una editorial aclaraba que los gobiernos de facto podían ser respetuosos de las instituciones libres fundamentales, mientras que existía la posibilidad de que aquellos surgidos de comicios populares resultaran dictatoriales y tiránicos (IsL, 1962: 4). Asimismo, en un artículo publicado en los tiempos del gobierno dictatorial de Juan C. Onganía, Enrique Loncán (1966:31) respaldaba el uso de la violencia, entendiéndola como el único recurso con el que contaban las minorías para defenderse de la opresión y la depredación de la que eran víctimas frente a las "mayorías circunstanciales” que las tiranizaban.

Esta operación de legitimación de las dictaduras no estaba restringida a los intelectuales argentinos. También la ensayaron, desde las páginas de IsL, el ordoliberal Wilhem Röpke (1959) y el periodista anticomunista William H. Chamberlain (1964) para apoyar el régimen, en España, del general Franco, cuyo modelo económico resultaba, a la vista de ambos autores, conforme a la doctrina del libre mercado. Por su parte, Sennholz (1963:25) celebraba que en la Argentina y en Chile los militares hubieran actuado para "suprimir los levantamientos de inspiración populistas” y desechar "elecciones populares que hubieran implantado [en esos países] el colectivismo desembozado.

Más allá de las adhesiones (ciertamente esporádicas y circunscriptas) que consiguieron en IsL las dictaduras, la demanda que se articulada con insistencia en sus editoriales y en los artículos de los ensayistas argentinos, apuntaba al uso, por parte de los Estados democráticos, de la violencia legítima, con la finalidad de reprimir los atentados a la propiedad privada. La figura del "guardián nocturno", comúnmente asociada a la concepción liberal-clásica del Estado, bastaba para satisfacer aquel requerimiento. Aun limitado a las funciones de defensa exterior, seguridad interior y provisión de justicia el Estado por el que clamaban los hombres del CDEL no era débil.

Por el contrario, tal como Benegas Lynch la imaginaba, la economía del poder estatal combinaba el respeto de la independencia de los individuos, la abstención de toda actuación que pudiera afectar sus libertades económicas, con el control de las situaciones y de los espacios en los que la propiedad privada resultara amenazada; un poder limitado a las funciones específicas pero eficaz. La lectura que le suscitaba, hacia comienzos de la década del '60, la coyuntura argentina, daba cuenta de una peligrosa "inversión” de aquel esquema gubernamental, según la cual el gobierno resultaba "fuerte” donde debía estar “ausente” y “débil” donde se justificaba el empleo de "toda su fuerza" para cumplir su cometido eficientemente (1962:16). Una reflexión semejante puede leerse en un artículo firmado bajo el seudónimo “Tranquilius” que IsL publicara en 1975. En el agitado contexto de violencia política que precedió al golpe de Estado de 1976, dicho trabajo trasuntaba la queja respecto de un Estado “celoso y absorbente” para intervenir en la producción y el comercio pero “débil para cumplir su obligación primordial” de garantizar la vida y los bienes de la población frente a los “ataques arteros de los que (...) [eran] objeto a diario por la subversión” (Tranquilius, 1975: 44).

\section{Reflexiones finales}

En un texto editado por John Goodman y Ramona Marotz Baden (1990), del National Center for Policy Analysis, que lleva por título Fighting the war of ideas in Latin America, el CDEL es distinguido como uno de los think-tanks que tuvieron el mérito de librar tempranamente en América Latina el combate por las ideas 
liberales. Si tenemos como ciertas las referencias con las que los editores introducen el capítulo del libro dedicado a la Argentina, -a la sazón, escrito por el hijo del fundador de la entidad, el economista Alberto Benegas Lynch (h)-, IsL habría llegado a tener hasta 3500 lectores. En la opinión de Goodman y Martoz Baden, el CDEL desempeñó un papel pionero en la organización de grupos de ideas dedicados a la difusión “militante” del liberalismo en la Argentina. Según surge del texto al que nos referimos, varios institutos de orientación liberal se fundaron en las décadas de 1970 y 1980 siguiendo el modelo del CDEL y a instancia de personas que habían estado asociadas a él.

Ciertamente, como se destaca en varios trabajos (Morresi, 2008, Nallim, 2014), el mismo desempeñó un lugar relevante para el revival de los estudios académicos liberales en los años '80, los cuales fueron promovidos, entre otras instituciones, desde la Escuela Superior de Economía y Administración de Empresas (ESEADE) fundada en 1978 por Alberto Benegas Lynch (h), la cual todavía continúa funcionando, aunque ya no está vinculada aquella familia.

Por el contrario, entre 1958 y 1976 la incidencia que IsL tuvo en relación a la orientación de la economía argentina, a los debates económicos y, más general, el impacto sobre el campo político y cultural, fue limitada. Aun así, entendemos que su análisis resulta significativo en atención a los dos ejes que vertebran los argumentos vertidos en este artículo: la interrogación de los modos a partir de los cuales la filosofía de la libertad procuró ser reactivada en la Argentina tras el derrocamiento del peronismo y la exploración de la participación que el CDEL tuvo en los procesos de organización y articulación de fuerzas a partir de los cuales el neoliberalismo se configuró como un proyecto colectivo transnacional.

En lugar de apostar a las ideas de la "economía social de mercado" o de la incipiente Escuela de Chicago, en IsL la reactivación del liberalismo dependió de una suerte de "retroversión histórica”. Como vimos, los hombres del CDEL encontraron, en la tradición argentina una "utopía liberal”, a la cual se remitieron para anclar la concepción elitista de democracia hacia la cual se sentían inclinados, fundar doctrinariamente la opción del "libre mercado" y clausurar las disputas al interior del campo liberal argentino, excluyendo de él aquellas opciones que admitían alguna suerte de intervencionismo económico.

La relectura de esa tradición fue clave para subordinar la democracia a los valores de la república y para demostrar la precedencia que, en la historia de la independencia argentina, había tenido la libertad económica por sobre la libertad política. Al insistir en el desacoplamiento del "liberalismo" y la "democracia" ambas operaciones habilitaron, como vimos, la articulación de discursos que permitían justificar el recurso (ciertamente excepcional) a la dictadura, como la aplicación de medidas (así, las proscripciones) que restringían, temporariamente, la ciudadanía política.

Esa clase de maniobras ideológicas, montadas a partir de ciertas vertientes del liberalismo argentino del siglo XIX, no pueden dejar de relacionarse con la participación que algunos de las personas que publicaban con cierta asiduidad en IsL tuvieron en grupos de ideas y/o asociaciones de intereses que promovieron y/o apoyaron, en distintas circunstancias, a las dictaduras militares argentinas. Tanto Benegas Lynch como Sánchez Sañudo tomaron parte de las conspiraciones que precedieron al golpe de 1955, mientras que Enrique Loncán integró el grupo Azcuénaga que desempeñara un papel destacado en relación al denominado Proceso de Reorganización Nacional.

Asimismo, según se desprende del estudio que realizamos, la batalla ideológica que ciertos intelectuales neoliberales y think tanks conservadores que defendían la ideología del libre mercado, estaban dando, desde los Estados Unidos y en pleno contexto de la Guerra Fría, contra diversas formas de "colectivismo", resonaba en las páginas de IsL. En la medida en que esa confrontación, de alcance transnacional, reconocía, como focos de interés predominantes el “anticomunismo” y el ataque a la “economía del desarrollo”, no dejó de interceptarse con los grandes temas de la coyuntura argentina, como el debate por el "desarrollo 
argentino”, la protesta sindical y el crecimiento de la violencia política.

La participación de la institución organizada a instancias de Benegas Lynch en el "proyecto neoliberal” fue, como sostuvimos, ambivalente. Por un lado, el CDEL se mostró por demás de consecuente con la apelación que Hayek había lanzado a los partidarios de la libertad, sobre la necesidad de dar la batalla de las ideas. En virtud de su intermediación, varios intelectuales neoliberales visitaron entre 1955 y 1976 el país. La institución se muñó, además, de una revista desde la cual divulgar ideas que permitieran reeducar a las elites en el espíritu de la libertad y de un sello editorial, en el que se publicaron los trabajos tanto de von Mises y sus discípulos, como de Hayek y de otros miembros encumbrados de la Sociedad Mont Pelèrin. Sin embargo, ni Benegas Lynch ni el pequeño núcleo de periodistas, economistas y ensayistas que orbitaban en torno al CDEL, daban al "neoliberalismo" otro valor que el de un término que expresaba un "renacimiento" del pensamiento a favor de la libertad.

\section{Notas}

1 A partir de 1959 dicha institución pasó a denominarse Centro de Estudios sobre la Libertad. Además de Benegas Lynch, que se desempeñaba como presidente y de Carlos Luzzetti, que oficiaba de vicepresidente, el CDEL estaba conformado por un secretario y un prosecretario, dos tesoreros, dos revisores de cuentas, un Consejo de Administración formado por varios vocales -entre los que se cuentan periodistas y ensayistas que solían escribir en IsL como Enrique Smith, Manuel Tagle y Carlos Sánchez Sañudo- y una Comisión de publicaciones, también integrada por algunos hombres que escribían en la revista, como Floreal González y Norberto Carca.

$\underline{2}$ Así, los diferentes ejes que organizan el artículo surgieron y se construyeron a partir del trabajo con la revista. En esa dirección, nos ocupamos de leer, seleccionar y disponer en diversas “series” los múltiples textos que conformaban cada uno de los números de IsL publicados entre 1958 y 1975. El corpus de documentos que quedó, así, organizado, está integrado por formulaciones discursivas extraídas de las “editoriales”, que, sin firma, abrían cada número; del material publicado en tres secciones especiales de la revista (denominadas, respectivamente, "Para la biblioteca del hombre libre”, "Verdades eternas” y "Para entrar en la materia”), así como de las diversas contribuciones de autores nacionales y extranjeros que bajo la forma, principal, de "artículos de opinión”, aparecieron a lo largo del período estudiado. En relación a estas últimas corresponde aclarar que pusimos especial atención en el análisis de los materiales firmados por personas que integraban, formalmente, la estructura institucional del CDEL, habían sido beneficiarios de alguna beca otorgada por dicha institución y/o formaban parte del catálogo de autores de su sello editorial.

$\underline{3}$ Configurada a lo largo del siglo XIX y comienzos del siglo XX en respuesta a un conjunto específico de problemas, la "tradición liberal” (Gallo, 1987) articuló de manera heterodoxa ideas políticas, instituciones y motivos culturales liberales con la preocupación por la construcción de la nación, la cual incluía la imposición del orden político y el éxito del desarrollo económico. Integrada, entre otros elementos, por un corpus de textos producidos por los intelectuales y políticos de las denominadas Generación de Mayo y Generación del '37, así como por la Constitución Nacional de 1853, tanto en sus discursos como en sus prácticas dicha tradición liberal fundacional estuvo atravesada por contradicciones y ambigüedades en torno a las cuestiones del sufragio, la intervención del Estado en la economía y la autoridad estatal (Nallim, 2014).

4 Una muy buena síntesis de la trayectoria del neoliberalismo, desde sus inicios en la II Post-Guerra hasta la década de 1990, que brinda un panorama de su ascenso hegemónico en diferentes contextos nacionales, se encuentra en Anderson (1995-6). 
$\underline{5}$ Sin inmiscuirse de manera directa y visible en el quehacer de la propaganda política, esta prestigiosa usina de pensamiento neoliberal transnacional (que reunía aproximadamente cada dos años a economistas, empresarios, periodistas, intelectuales y políticos liberales procedentes, principalmente, de Europa y de los Estados Unidos) contribuyó de sobremanera a que los principios neoliberales se convirtiesen, a partir de la década de 1970, en "soluciones políticas” aceptables. Nacida en plena Guerra Fría, al igual que el Congreso para la Libertad de la Cultura fue un instrumento de lucha contra el comunismo y, más extensamente contra toda forma de colectivismo. Sobre la historia de la Sociedad Mont Pelèrin véase Hartwell (1995) Denord (2002/5), Mirowski y Plehwe (2009).

$\underline{6}$ Entre los múltiples intelectuales, economistas y/o activistas (así, periodistas, funcionarios de think-tanks), tanto europeos como estadounidenses, que formaban parte activa de las redes transnacionales aplicadas desde el fin de la II Guerra a la reactivación y la renovación del liberalismo, en el período que investigamos aquí, visitaron el país Friedrich Hayek (1957), Leonard Read (1958), Ludwig von Mises (1959), Wilhem Röpke (1960), Albert Hunold (1962), Sylvester Petro (1962), Arthur Shenfield (1962), Henry Hazlitt (1964), Benjamin Rogge (1965); la mayor parte de ellos invitados por el CDEL.

$\underline{7}$ El CLC funcionó promoviendo eventos culturales (tales como encuentros, conferencias, conciertos, etc.), publicando libros y revistas pero, sobre todo, tejiendo una vasta red de relaciones internacionales entre actores procedentes del mundo de la intelectualidad y la política (Jannello, 2012a, 2012b). En América Latina, dónde desembarcó en 1953, tuvo una vida sumamente activa, de la cual dan testimonio los Cuadernos del Congreso por la Libertad de la Cultura, la revista que fungía como órgano oficial de la entidad. En cuanto a la actividad desarrollada por el CLC en América Latina y, en particular, en Argentina, puede consultarse el artículo de Nállim (2012) y los trabajos de Jannello (2012a, 2012b, 2012c, 2015). Un análisis que también aborda el quehacer del Congreso en aquella región, si bien focalizado sobre la revista "Cuadernos...”, se encuentra en Ruiz Galvete (2006).

$\underline{8}$ Benegas Lynch participó de la Asociación Patriótica Argentina (APA), liderada por el almirante Isaac Rojas, uno de los espacios de las conspiraciones que precedieron al golpe de 1955, como, asimismo, de la Comisión de Afirmación de la Revolución Libertadora (Vicente 2015).

$\underline{9}$ Entre los distintos intelectuales, economistas y militantes de las ideas liberales que llegaron la Argentina invitados por el CDEL, la visita, en 1959, de Ludwig von Mises ocupa un lugar destacado. Su presencia fue un éxito para la institución: las multitudinarias charlas que impartió en la Facultad de Ciencias Económicas de la Universidad de Buenos Aires ocuparon un lugar relevante en los medios de prensa, además de ser publicadas por el sello del CDEL bajo el título "Seis conferencias en Buenos Aires”.

10 Este ex becario del CDEL tuvo participación en el denominado "Grupo Azcuénaga" uno de los centros de discusión de ideas que brindaron apoyo ideológico al golpe de Estado de 1976. Asimismo, en 1985 fundó, junto a otra ex becaria del CDEL, Luisa Zorraquín de Marcos el Instituto de Estudios Económicos y de Ética Social (Goodman y Marotz-Baden, 1990).

11 Entre otros profesionales, también Fernando Benegas, abogado y miembro del Consejo de Administración del CDEL, fue becado por la FEE para tomar un curso en Nueva York bajo supervisión de Read.

12 IsL ofrecía al lector ensayos de Alberto Benegas Lynch y de intelectuales y periodistas argentinos, varios de los cuales reunían la doble condición de ser asiduos colaboradores del diario liberal "La Prensa” y de integrar el catálogo de autores del CDEL; así, por ejemplo, el empresario del sector automotor y ensayista Manuel Tagle, el almirante retirado Carlos Sánchez Sañudo y el periodista Rodolfo Luque.

13 Como apunta Morresi (2008:45) Benegas Lynch desconfiaba, asimismo, de la conveniencia de inmiscuirse directamente en política. 
14 Sobre esta y otras interpretaciones que nutrieron el intenso proceso de relectura del peronismo que se desarrolló en Argentina a partir de 1955 véase Terán (1991), Neiburg (1998) y Sarlo (2007).

$\underline{15}$ Sobre las "tensiones" que atraviesan el pensamiento neoliberal y las formas en que las mismas intentan ser administradas véase Mirowski (2009)

16 Este rasgo distintivo del neoliberalismo considerado en su conjunto ha sido destacado por Denord (2002/5), Peck (2008), Plewhe y Mirowski (2009) y Foucault (2012).

17 La expresión "paleoliberalismo” fue utilizada por Alexander Rüstow, intelectual alemán vinculado a la vertiente del ordoliberalismo alemán, para referirse al liberalismo manchesteriano, al cual acusaba -junto a otros intelectuales procedentes de ese linaje neoliberal- de “ceguera sociológica”. Sobre esta corriente, véase, entre otros aportes, Bohmler (1998), Ptak (2009) y Foucault (2012).

18 Para von Mises (1968:26) la ciencia económica era una "praxeología”, es decir, una teoría y un método que teniendo como objeto la "acción humana" se ocupa de analizar las elecciones humanas, el modo en que los individuos prefieren y asignan ciertos medios para alcanzar ciertos fines. Este análisis presupone que el acto a través del cual el individuo elige entre bienes alternativos para alcanzar un fin es subjetivo, puesto que esa opción depende del lugar de "medio" o "fin intermedio" en el cual el sujeto ha colocado dicho bien, dependiendo de su escala valorativa (Zanotti,1990).

19 La publicación en 1961 de la obra cumbre de este último, La acción humana en la editorial española "Fundación Villalonga”, con la traducción de Joaquín Reig Albiol, fue muy difundida por el CDEL. Esa publicación fue celebrada por las múltiples instituciones que, dispersas en distintos países de América Latina, daban la "batalla por la libertad”. Entre esas usinas, de las que aparecían esporádicas noticias en IsL, estaban el Instituto de Investigaciones Sociales y Económicas de México, dirigido por Gustavo Velasco, y el Centro de Estudios Económico-Sociales de Guatemala, del cual era miembro fundador Manuel Ayau. Integrantes de la Sociedad Mont Pelèrin ambos intelectuales tuvieron gran protagonismo en la divulgación del pensamiento neoliberal en América Latina.

20 Como señalara von Mises (1960:5), en una formulación destacada en IsL:“dónde hay un menor grado de desigualdad en la riqueza hay también un nivel medio de vida inferior”.

21 Dos economistas argentinos que están inscriptos en las redes neoliberales transnacionales, como Alejandro Chafuen, presidente de la Fundación Atlas, y Juan Carlos Cachanovsky, que fue decano de la Escuela de Negocios de la (neoliberal) Universidad Francisco Marroquín, se doctoraron con Sennholz.

$\underline{22}$ Sobre los diversos “momentos” del liberalismo argentino del siglo XIX véase Palti (1994-1995).

$\underline{23}$ En relación a la apropiación que los intelectuales socialistas hicieron de esa tradición en el marco de la lucha antifascista véase Bisso (2001). Asimismo, la relación que los intelectuales comunistas mantuvieron con el "pasado liberal” a partir de la década del '30 y hasta la década del '50, es objeto de análisis en los trabajos de Cattaruzza (2007), Pasolini (2005, 2013) y Petra (2010, 2013a, 2013b).

$\underline{24}$ Ghioldi, A. (1944). Bases de la pedagogía popular. Buenos Aires: La Vanguardia, p.36, citado por Martínez Mazzola (2011a:48).

$\underline{25}$ En 1958 el Partido Socialista quedó dividido en dos fracciones: mientras el Partido Socialista Democrático representaba, como apuntamos, la línea liberal, el Partido Socialista Nacional encarnaba al sector de izquierda del partido. Sobre el derrotero del socialismo a partir de 1955 pueden consultarse, entre otros, los trabajos de Blanco (2000) y Tortti (2009, 2016).

$\underline{26}$ Ghioldi -quién prestó un fuerte apoyo a la Revolución Libertadora- defendía un sistema político 
excluyente y era de la idea de que la crisis política posterior a 1955 debía enfrentarse mediante la represión de los sectores peronistas. Asimismo, se manifestó a favor de los fusilamientos de José León Suarez (Blanco, 2002).

$\underline{27}$ El debate abierto por Agosti no se limitó a la relación de los comunistas con la tradición liberal, sino que incluía a la intelectualidad argentina en general. Como apunta Pasolini (2013:14), además de la incidencia de la situación política nacional y de las decisiones de la política internacional del comunismo, en la instalación de esa discusión también pesó el descubrimiento, por parte de Agosti, de las ideas de Gramsci, particularmente, de la noción de bloque histórico "nacional-popular" y de aquella relativa al papel que desempeñan los intelectuales en tanto organizadores del mundo de la cultura.

$\underline{28}$ Así, en una conferencia pronunciada en 1928 en la Universidad de La Plata, Aníbal Ponce, un intelectual que sin afiliarse al Partido Comunista, giró en su órbita, transformándose con el tiempo en uno de sus más notorios héroes culturales, afirmó que los principios de la revolución de mayo no se habían realizado totalmente, constituyendo un programa para el presente y para el futuro, cuyos núcleos serian la soberanía nacional y la justicia social (Ponce, A. (1939). Examen de conciencia, en El viento en el mundo. El Ateneo: Buenos Aires, p.32; citado por Cattaruzza, 2007:176).

$\underline{29}$ Tagle homologaba el régimen rosista al peronismo e inscribía ambas configuraciones en el linaje de los totalitarismos. La operación no era novedosa ni se reducía al ámbito del pensamiento liberal-conservador: ya en la década del ' 40 intelectuales procedentes de las filas del socialismo y del comunismo ensayaron un movimiento semejante, condenando (en contraposición con las maniobras revisionistas) el gobierno de Rosas por "totalitario" y comparándolo con el gobierno de Perón y a ambos líderes con Hitler. Un análisis detallado de esas operaciones de lectura en el ámbito del socialismo se encuentra en Bisso (2001), Herrera (2005) y Martínez Mazzola (2011b). Mientras el primero se focaliza en su funcionamiento en el contexto de la lucha antifascista, los estudios de Herrera y Martínez Mazzola se concentran en analizar la caracterización que, desde el socialismo, se hizo del peronismo en términos de totalitarismo. Para el caso de la intelectualidad comunista pueden consultarse los trabajos de Petra (2013a, 2013b).

\section{Bibliografía}

Abdala, R.O. (1961). Un excelente muestra del pensamiento liberal. Ideas sobre la Libertad, No 7, pp.58-64.

Alsogaray, A. (1968). Bases para la Acción Política Futura. Buenos Aires: Atlántida.

Anderson, P. (1995-96). Un balance del neoliberalismo. El rodaballo, № 3, pp.8-13.

Benegas, F.(1966). ¿Es eso desarrollo? Ideas sobre la Libertad, No 23, pp. 46-52.

Benegas, F. (1970). Mitos y razones. Ideas sobre la Libertad, Nº 27, pp. 44-47.

Benegas Lynch, A. (1959). Libertad: más actitudes positivas. Ideas sobre la Libertad, № 3, pp.49-53.

Benegas Lynch, A. (1960). Mayo y la libertad económica. Ideas sobre la Libertad, No 6, pp. 11-16.

Benegas Lynch, A. (1962). Teoría económica y acción política. Ideas sobre la Libertad, No 11, pp.14-18.

Benegas Lynch, A. (1963a). Eficacia anticomunista. Ideas sobre la Libertad, No 14, pp.34-38.

Benegas Lynch, A. (1963b). Libertad, civilización y moneda. Ideas sobre la Libertad, Nº16, pp.7-20.

Benegas Lynch, A. (1964). La propiedad: imprescindible factor de progreso, Ideas sobre la Libertad, $\mathrm{N}^{\circ} 17$, pp. 16-19. 
Benegas Lynch, A. (1968). ¿ ¿iene vigencia hoy una política liberal?. Ideas sobre la Libertad, № 25, pp.2-7.

Benegas Lynch (1971). El progreso argentino y la Constitución de 1853, en F. Pinedo, La Argentina. Su posición y rango en el mundo. Buenos Aires: Sudamericana.

Benegas Lynch, A. (1973). Corrupción de la democracia y contrabando ideológico. Ideas sobre la Libertad, $\mathrm{N}^{\circ}$ 30, pp.3-7.

Betria, M. (2012).La ciudadanía política en el pensamiento de Esteban Echeverría. Temas y Debates, № 23, pp. $57-70$.

Biglaiser, G. (2002). The internationalization of Chicago's Economics in Latin America. Economic Development and Cultural Change, Vol.50, № 2, pp.269-286.

Bisso, A. (2001). La recepción de la tradición liberal por parte del antifascismo argentino. Estudios Interdisciplinarios de América Latina y el Caribe, 12 (2).

Bisso, A. (2007). El antifascismo argentino. Buenos Aires: CeDInCi. Buenos Libros.

Blanco, C. (2000). El partido socialista en los '60: enfrentamientos, reagrupamientos y rupturas. Sociohistórica, N 7. Disponible en: http://www.sociohistorica.fahce.unlp.edu.ar

Cattaruzza, A. (2007). Visiones del pasado y tradiciones nacionales en el Partido Comunista Argentino (ca. 1925-1950). A Contracorriente , 5 (1), pp169-195.

Chamberlain, W.H. (1964). El ocaso de los planificadores. Ideas sobre la Libertad, No 18, pp.42-48.

Bohmler, A. (1998). El ideal cultural del liberalismo: la filosofía política del ordo-liberalismo. Madrid: Unión Editorial.

Croce, B. (1952). Ética y Política. Buenos Aires: Imán.

Denord, F. (2002/5). Le prophète, le pèlerin et le missionnaire. La circulation internationale du néolibéralisme et ses acteurs. Actes de la recherche en sciences sociales, № 145, pp. 9-20.

Foucault, M. (2012). Nacimiento de la biopolítica. Buenos Aires: FCE.

Fox, W. (1964). La Alianza para el Progreso Tiene que Fracasar. Ideas sobre la Libertad, No 19, pp.47-50.

Gallo, E., Cornblit, O., Ribas, A., Chafuen, A. et al. (1984). Liberalismo y Sociedad. Ensayos en honor del profesor dr. Alberto Benegas Lynch. Buenos Aires: Macchi.

Gallo, E. (1987). Tradición liberal argentina, Estudios Públicos, № 27, pp.351-378

Georgieff, G. (2008). Nación y revolución. Itinerarios de una controversia en Argentina (1960-1970). Buenos Aires: Prometeo.

González, F. (1969). Masas y élites. Ideas sobre la Libertad, № 26, pp.19-27.

González, F. (1973). De prácticas y teorías. Ideas sobre la Libertad, № 29, pp.26-35.

Goodman, J. C. y Marotz-Baden, R. (1990). The war of ideas in Argentina, en Goodman J.C. y MarotzBaden, R. (eds.), Fighting the war of ideas in Latin America (115-121). Dallas: National Center for Policy Analysis.

Grondona, A. (2011). Las voces del desierto. Aportes para una genealogía del neoliberalismo como racionalidad de gobierno en la Argentina (1955-1975). La revista del CCC, $\mathrm{N}^{\circ}$ 13. Disponible en http://www.centrocultural.coop/revista/exportarpdf.php?id=271. 
Haidar, V. (2015a) ¿Gobernar a través de la libertad? Escrutando las heterogeneidades de la gubernamentalidad neoliberal en los discursos de Álvaro Alsogaray (Argentina, 1955-1973). A contracorriente, Vol.12, №2, pp. 1-41.

Haidar, V. (2015b). La polémica liberal con los desarrollismos: un análisis del pensamiento de Álvaro Alsogaray y de Federico Pinedo entre 1958 y 1973. Nuevo Mundo. Mundos Nuevos, diciembre de 2015. Disponible en: http://nuevomundo.revues.org/68478 ; DOI : 10.4000/nuevomundo.68478

Haidar, V. (2016a). ¿“Cumplimiento escrupuloso de la ley”?: las interpretaciones liberales de la "legalidad” (Argentina, 1955 -1973). Postdata, № 21, pp.129-169.

Haidar, V. (2016b). “El liberalismo y la cuestión de los “hombres libres”: un análisis de su problematización en el campo liberal argentino entre 1955 y 1973”. Espiral. Estudios sobre Estado y Sociedad, № 66, pp.4175.

Hartwell, M. (1995). A History of the Mont Pelerin Society. Indianapolis: Liberty Fund.

Hayek, F. (1949). The intellectuals and socialism. The University of Chicago Law Review, pp. 417-433.

Hayek, F. (1958). Renacimiento del Liberalismo. Ideas sobre la Libertad, No 1, pp.11-16.

Hayek, F. (1992).The economics of the 1920s as seen from Vienna, en Klein, P.G. (ed.), The collected works of F.A. Hayek, volume IV: the fortunes of liberalism (19-37). Chicago: University of Chicago Press.

Hazlitt, H. (1967). La falacia de la ayuda exterior. Ideas sobre la Libertad, № 24, pp. 29-38.

Heredia, M. (2001). La identificación del enemigo. La ideología liberal-conservadora frente a los conflictos sociales y políticos de los años sesenta, Sociohistórica, No 1, pp.83-120.

Heredia, M. (2002). Política y liberalismo conservador a través de las editoriales de la prensa tradicional en los años '70 y '90, en Levy, B. (org.), Crisis y Conflicto en el capitalismo latinoamericano: lecturas políticas (57-103), Buenos Aires: Clacso.

Herrera, C.M. (2005). ¿La hipótesis de Ghioldi? El socialismo y la caracterización el peronismo, en Camarero, H. y Herrera, C.M., El Partido Socialista en Argentina. Buenos Aires: Prometeo.

Ideas sobre la Libertad (1958). Mensajes para ISL. Ideas sobre la Libertad, Nº1, pp.4-5.

Ideas sobre la Libertad (1959).Un año de labor. Ideas sobre la Libertad, Nº 4, pp. 2-3.

Ideas sobre la Libertad (1961). Predicar a convencidos. Ideas sobre la Libertad, No 7, pp.2-4.

Ideas sobre la Libertad (1962). Importancia de la verdad. Ideas sobre la Libertad, Nº 11, pp. 2-4.

Ideas sobre la Libertad (1964). El Centro y el Club. Ideas sobre la Libertad, Nº 18, pp.2-3.

Ideas sobre la Libertad (1970). La invasión comunista. Ideas sobre la Libertad, No 27, pp.2-3.

Jannello, K. (2012a). Intelectuales, revistas, redes editoriales y Guerra Fría. El Congreso por la Libertad de la Cultura en Argentina y América Latina, Buenos Aires: Tesis de Maestría IDAES/UNSAM.

Jannello, K. (2012b). El Congreso por la Libertad de la Cultura: el caso chileno y la disputa por las "ideas fuerza” de la Guerra Fría”. Revista www.izquierdas.cl, Nº 14, diciembre 2012, pp. 14-52.

Jannello, K. (2012c). Las editoriales socialistas bajo la guerra fría cultural: Bases, Asociación Argentina por la Libertad de la Cultura, Líbera. Primer Coloquio Argentino de Estudios sobre el Libro y la Edición. Disponible en: http://coloquiolibroyedicion.fahce.unlp.edu.ar 
Jannello, K. (2015). La intelectualidad liberal bajo la Guerra Fría: La sede argentina del Congreso por la Libertad de la Cultura (1953-1964). Acta Sociológica. Nº 68, pp.9-47.

Llamazares Valduvieco, I. (1995). Las transformaciones del discurso liberal-conservador en la Argentina contemporánea: un examen del pensamiento político de Federico Pinedo y Álvaro Alsogaray. América Latina Hoy, vol.12, pp.143-154.

Loncan, E. (1966). Democracia de unos y otros. Ideas sobre la Libertad, No 21, pp.29-32.

Loncan, E. (1975). Los países pobres y la inversión externa. Ideas sobre la Libertad, No31, pp. 9-11.

Luzzetti, C. (1961). El desarrollo económico y los préstamos internacionales. Ideas sobre la Libertad, № 7, pp.9-11.

Martínez Mazzola, R. (2011a). Justo, Korn, Ghioldi. El partido socialista y la tradición liberal. Papeles de trabajo, $\mathrm{N}^{\circ}$ 8, pp.35-52.

Martínez Mazzola, R. (2011b). Nacionalismo, peronismo, comunismo. Los usos del totalitarismo en el discurso del Partido Socialista Argentino (1946-1953). Prismas, № 15, pp.105-125.

Mirowski, P. (2009). Defining Neoliberalism. Mirowski, P. y Plehwe, D. (eds.) (2009). The Road from MontPèlerin. The Making of the Neoliberal Thought Collective. Harvard University Press: Cambridge.

Mirowski, P. y Plehwe, D. (eds.) (2009). The Road from Mont-Pèlerin. The Making of the Neoliberal Thought Collective (417-455). Harvard University Press: Cambridge.

Mitre, B. (1975). Origen de la libertad económica en el Río de la Plata. Ideas sobre la Libertad, Nº 31, pp.5760.

Morresi, S. (2007). ¿Más allá del neoliberalismo? Estado y neoliberalismo en los años noventa en Rinesi, E., Nardacchione, G. y Vommaro, G. (comps.), Las lentes de Víctor Hugo. Transformaciones políticas y desafíos teóricos en la Argentina reciente (pp.117-150). Buenos Aires: UNGS-Prometeo.

Morresi, S. (2008). La nueva derecha argentina. Buenos Aires: Biblioteca Nacional- UNGS.

Morresi, S. (2009). Neoliberales antes del neoliberalismo, en Soprano, G. y Frederic, S. (eds.), Política y variaciones de escalas en el análisis de la Argentina (pp.321-350). Buenos Aires: UNGS-Prometeo.

Morresi, S. (2010). El liberalismo conservador y la ideología del Proceso de Reorganización Nacional. Sociohistórica, № 27, pp. 103-135.

Morresi, S. (2011). Las raíces del neoliberalismo argentino (1930-1985), en Rossi, M.A. y López, A. (comp.), Crisis y metamorfosis del Estado argentino: el paradigma neoliberal en los noventa (pp. 47-70). Buenos Aires: Luxemburg.

Nállim, J. (2012). "Redes transnacionales, antiperonismo y Guerra Fría: Los orígenes de la Asociación Argentina por la Libertad de la Cultura”. Prismas, vol.1, No 1 .

Nállim, J. (2014). Transformación y crisis del liberalismo. Su desarrollo en la Argentina en el período 19301955. Buenos Aires: Gedisa

Neiburg, F. (1998). Los intelectuales y la invención del peronismo. Buenos Aires: Alianza.

Odisio, J. y Rougier, M. (2014). Los críticos de la industrialización. Ideas y propuestas de Política y Economía a principios de los setenta, en Rougier, M., Gálvez, E., Jerez, P. et al., Perspectivas sobre la Industria, 2 (39-67). Buenos Aires: FCE-UBA. 
Palti, E. (1994-1995). Orden político y ciudadanía. Problemas y debates en el liberalismo argentino en el siglo XIX. Estudios Interdisciplinarios de América Latina y el Caribe,vol.5, № 2.

Pasolini, R. (2005). El nacimiento de una sensibilidad política. Cultura antifascista, comunismo y nación en la Argentina: entre la AIAPE y el Congreso Argentino de la Cultura, 1935-1955. Desarrollo Económico, vol. 45, No 179 , pp. 403-433.

Pasolini, R. (2013). Los marxistas liberales. Buenos Aires: Sudamericana.

Peck, J. (2008). Remaking laissez faire. Progress in Human Geography, № 32, vol.1, pp. 3-43.

Petra, A.C. (2010). Cosmopolitismo y nación. Los intelectuales comunistas argentinos en tiempos de la guerra fría (1947-1956). Contemporánea. Historia y Problemas del siglo XX, № 1, pp.51-73.

Petra, A. C. (2013a). Intelectuales comunistas en la Argentina (1945-1963) [en línea]. Tesis de posgrado. Universidad Nacional de La Plata. Facultad de Humanidades y Ciencias de la Educación. En Memoria Académica. Disponible en: http://www.memoria.fahce.unlp.edu.ar/tesis/te.896/te.896.pdf

Petra, A.C. (2013b). Cultura comunista y guerra fría: Los intelectuales y el movimiento por la paz en la Argentina. Cuadernos de Historia, No 38, pp.99-130.

Phillips-Fein, K. (2009). Business Conservaties and the Mont Pelèrin Society, en Mirowski, P. y Plehwe, D. (eds.) The Road from Mont-Pèlerin. The Making of the Neoliberal Thought Collective (280-301). Harvard University Press: Cambridge.

Plewhe, D. (2009). Introduction, en Mirowski, P. y Plehwe, D., The Road from Mont-Pèlerin. The Making of the Neoliberal Thought Collective (1-42). Harvard University Press: Cambridge.

Ptak, R. (2009). Neoliberalism in Germany. Revisiting the Ordoliberal Foundations of the Social Market Economy, en Mirowski, P. y Plehwe, D., The Road from Mont-Pèlerin. The Making of the Neoliberal Thought Collective (98-138). Harvard University Press: Cambridge.

Ponza, P. (2010). Intelectuales y violencia política. 1955-1973. Córdoba: Babel.

Read, L. (1959). “Abandono de la integridad”. Ideas sobre la Libertad, N 4, pp.5-16.

Röpke, W. (1959). La libertad de sentirse progresista. Ideas sobre la Libertad, № 3,pp. 19-29.

Ruiz Galvete, M. (2006). Cuadernos del Congreso por la Libertad de la Cultura: anticomunismo y Guerra Fría en América Latina. El argonauta español, $\mathrm{N}^{\circ} 3 . \quad$ Disponible en: http://argonauta.imageson.org/document75.html

Sánchez Sañudo, C. (1965). La encrucijada de la libertad en Hazlitt, H., Sánchez Sañudo, C., Tagle, M. y Benegas Lynch, A. El Estado y la libertad (pp.41-100). Buenos Aires: Centro de Estudios sobre la Libertad.

Sarlo, B. (2007). La batalla de las ideas. Buenos Aires: Emecé.

Sennholz, H. F. (1959). El mito del colonialismo capitalista. Ideas sobre la Libertad, No 4, pp. 57-64.

Sennholz, H. F.(1962). La política exterior de Estados Unidos promueve el socialismo. Ideas sobre la Libertad, No 11 , pp. 24-26.

Sennholz, H.F. (1963). Alianza para el Progreso. Ideas sobre la Libertad, No 16, pp. 21-29.

Sickle, J.V (1962). Viejas y nuevas teorías sobre el desarrollo. Ideas sobre la Libertad, No 10, pp. 40-48.

Sigal, S. (2002). Intelectuales y poder en Argentina. La década del sesenta. Buenos Aires: Siglo XXI 
Sigal, S. y Verón, E. (1988). Perón o muerte. Buenos Aires: Hyspamérica.

Smith, H. (1963). La crisis argentina. Ideas sobre la Libertad, No 13, pp.32-40.

Tagle, M. (1959). Tendencias antiliberales de la democracia en América Latina. Ideas sobre la Libertad, N³, pp. 4-8.

Tagle, M. (1964). Dos maneras de combatir la inflación. Ideas sobre la Libertad, №17, pp. 8-12.

Tagle, Manuel (1972). Los dos significados de la palabra proscripción. Ideas sobre la Libertad, № 28, pp.1216.

Terán, O. (1991). Nuestros Años Sesenta. Buenos Aires: Punto Sur.

Tortti, M. C. (2009). El “viejo” Partido Socialista y los orígenes de la "nueva” izquierda. Buenos Aires: Prometeo.

Tortti, M.C. (2016). La izquierda socialista de los 60 y el “camino propio” de la Revolución argentina. Contemporánea. Historia y problemas del siglo XX, vol. 7, pp.67-86.

Tranquillius (1975). Dejad hacer, dejad pasar. Ideas sobre la Libertad, No 30, pp. 42-44.

Velasco, G. (1959). El camino hacia el progreso económico. Ideas sobre la Libertad, No 4, pp.19-25.

Verón, E. (1996). La palabra adversativa, en El discurso político (pp.13-26). Buenos Aires: Hachette.

Viana, J.M. (2009). El giro ético en el pensamiento socialista argentino: del subjetivismo de Alejandro Korn al antipopulismo de Américo Ghioldi, ponencia presentada en las "XII Jornadas Interescuelas-Departamentos de Historia”, San Carlos de Bariloche, 28 al 31 de octubre.

Vicente, (2013a). Lo que fue y lo que nunca será: (de)ontologías de la Argentina en los intelectuales liberalconservadores durante el peronismo. A Contracorriente, 11 (1), pp. 86-109.

Vicente, M. (2013b). Los furores de una demagogia destructora: sociedad de masas, liderazgo político y estado en la trayectoria político-intelectual de Federico Pinedo. Nuevo Mundo, puesto en línea el 24 de julio de 2013, consultado el 19 de enero de 2014. http://nuevomundo.revues.org/65654

Vicente, M. (2015). De la refundación al ocaso: los intelectuales liberal-conservadores ante la última dictadura. La Plata: UNLP; Los Polvorines: UNGS; Posadas: Universidad Nacional de Misiones.

Von Mises, L. (1960). Desigualdad de riquezas e ingresos. Ideas sobre la Libertad, Nº 6, pp.5-9.

Von Mises, L. (1968). La acción humana. Madrid: Sopec.

Zanca, J.(2013). Cristianos Antifascitas. Buenos Aires: Siglo Veintiuno.

Zanotti,G. (1990). Fundamentos filosóficos y Epistemológicos de la Praxeología. Tesis para optar al grado de Doctor en Filosofía. Universidad Católica Argentina. 